\title{
Scenario Analysis of Carbon Emissions of China's Power Industry Based on the Improved Particle Swarm Optimization-Support Vector Machine Model
}

\author{
Jianguo Zhou, Fengtao Guang*, Ruiping Tang \\ Department of Economics and Management, North China Electric Power University, \\ 689 Huadian Road, Baoding 071000, China
}

Received: 6 April 2017

Accepted: 26 May 2017

\begin{abstract}
The power industry, as the primary source of carbon emissions across China, should take more responsibility to effectively reduce carbon emissions. Affected by various factors, carbon emissions from the power industry show non-linear and non-stationary characteristics. To forecast carbon emissions precisely and efficiently, this paper proposes an improved particle swarm optimization (IPSO)-support vector machine (SVM) model combined with scenario analysis. Grey relativity analysis (GRA) is applied to identify and construe the major influencing factors. Based on factors including economic growth, urbanization rate, total electricity consumption, net coal consumption rate, and thermal power installed capacity, 48 kinds of development scenarios are set during 2016-20. Compared with other methods, the effectiveness of IPSOSVM has been proved to have the best forecasting performance. The prediction results indicate that carbon emissions from China's power industry will be $128691.59-149137.32 \mathrm{kt}$ in 2020 . And the influencing level of each factor differs a lot in different development scenarios. Furthermore, there exists a certain decoupling between carbon emissions of China's power industry and economic growth.
\end{abstract}

Keywords: carbon emissions, power industry, scenario analysis, IPSO-SVM model

\section{Introduction}

Nowadays, one of the most important issues regarding environmental challenges is global warming, which stems from trapping greenhouse gases (GHS) in the atmosphere, causing climate changes at any point of the world [1]. Energy-related carbon emissions, as the primary source of

*e-mail: Guangft@126.com
GHS, undertake the main responsibility for climate change and environmental degradation. However, slightly more than $40 \%$ of the global energy-related carbon emissions are attributable to emissions from electricity and heat production [2]. Thus, the carbon emissions from power industry are of major environmental concern.

As a supplier of national energy and power, the power industry is the pillar industry and the lifeblood of national economic development for China. Since implementation of the reform and opening up, the power industry has experienced more than 20 years of development and has 
already become an important strength of the Chinese economy. But although the power industry has made remarkable progress, we cannot ignore the fact that it is suffering from serious problems such as high energy consumption and large-scale of carbon emissions.

Data from the International Energy Agency (IEA) shows that China has become a big country in respect to carbon emissions [3]. Much of the blame should be down to the power industry. It turns out to be one of the biggest emitters of carbon, accounting for $40 \%$ of total carbon emissions in China [4]. Moreover, electricity plays an increasingly important part in terminal energy structure year by year. The proportion of the consumption of the electricity increased to $15.85 \%$ in 2014 from $9.62 \%$ in 1995 . So it is noticeable that the power industry will be a major object of the work of energy conservation and carbon emissions reduction of the government. To shoulder the responsibility and accomplish the task, scientific and reasonable forecast models based on in-depth analysis of influencing factors is extremely important, and corresponding policies and measures must be implemented.

In the process of analyzing the influencing factors of carbon emissions, GDP needs to be deemed an important factor for consideration. The relationship between carbon emissions and economic growth is a special issue related to ecological environment and eco-environmental quality and economic development. Based on the hypothesis of the Environmental Kuznets Curve (EKC), many scholars go into this relationship [5-7]. Schmalesee et al. [5] studied the relationship between carbon emissions and per capita income in developed countries, and found that it resemble an inverted "U." Arouri et al. [6] took Middle Eastern and North American countries for research objects and concluded that there is an inverted U-type EKC between economic growth and carbon emissions. Saboori et al. [7] selected Malaysia for investigation and further strengthened the evidence of an inverted U-type linking carbon emissions with economic growth. However, Galeotti et al. [8] and Wang et al. [9] confirmed that the curve shape of the relationship carbon emissions and economic growth is like the shape of an "N." Besides EKC hypothesis, co-integration and the Granger causality test are also extensively used to research the relationship between carbon emissions and economic growth. Wu et al. [10] corroborated that mass fossil energy consumption is the primary cause of rapidly increasing carbon emissions and it exists as a co-integrated relationship between carbon emissions and economic growth by using the cointegration test and the Granger causality test.

Besides GDP, carbon emissions are affected by other factors as well. Taking Beijing as an example, Mi et al. [11] proved that the optimization and readjustment of industrial structure could be expected to eventually limit energy consumption and carbon emissions. Daly et al. [12] found that the progress of a technological level plays an important role in the reduction of carbon emissions in the United Kingdom. Muhammad Shahbaz [13] applied the ARDL bounds testing approach to examine the long relationship between urbanization and carbon emissions in the presence of structural breaks and found that the relationship between urbanization level and carbon emissions is positive in the United Arab Emirates. Fan et al. [14] adopted the STIRPAT model to analyze the impact of population on carbon emissions in China. Apart from that, Su and Ang [15] decomposed China's carbon emissions into emission intensity, energy structure, and energy intensity with the structural decomposition analysis approach, and demonstrated that the decline in carbon emission intensity is largely inhibited by the increase of carbon emissions. In addition to the influencing factors, trade [16], imports, and exports [17] are also the driving factors of carbon emissions.

The second one is based on various methods to forecast carbon emissions. Wang and Dang [18] improved the traditional model of $\operatorname{GM}(1,1)$ and researched carbon emission prediction in China's Jiangsu Province. Wang [19] divided the data of Chinese gross domestic product and carbon emissions from fossil energy consumption of 1953-2013 into 15 stages and used the non-linear grey model to quantify future Chinese carbon emissions from 2014 to 2020. Du et al. [20] verified that Chinese provincial carbon emissions can be classified into five categories by K-means clustering algorithm and forecasted provincial carbon emissions from 2011 to 2020 by the logistic model. Sun [21] classified Chinese total carbon emissions in accordance with industry and analyzed the carbon emissions trend of residential consumption and the three major industries, which include the primary, secondary, and tertiary industries, and predicted different types of carbon emissions by least squares support vector machine (LSSVM). Liu et al. [22] forecasted the gross carbon dioxide in China from 2013 to 2020 by employing the system dynamics model. Gambhir et al. [23] adopted the hybrid modeling method to forecast Chinese carbon emissions in 2050. According to the mentioned forecasting results, we know that gray prediction, logistic model, and artificial intelligent algorithm models are widely applied into carbon emissions, and any of them have their own characteristics and spheres of application.

In contrast to other methods, scenario analysis is becoming more and more popular in the research field of carbon emissions. Compared with the previous literature, it may therefore be concluded that an enormous amount of research on carbon emissions focuses on the national and regional levels, but there have been fewer studies related to carbon emissions of the power industry for China. Zhang [24] explored the carbon emissions reduction potentials for China's power industry under different scenarios by employing the long-range energy alternatives planning (LEAP) model. Yuan [25] designed two energy conservation and emissions reduction scenarios to study the future energy conservation potential of China's electricity sector.

In this paper, the principal purpose of the study is to forecast carbon emissions of China's power industry based on scenario analysis. In order to improve the precision of the prediction, a hybrid model, which 
combines improved particle swarm optimization (IPSO) and support vector machine (SVM), is adopted to predict carbon emissions. The parameters in SVM are optimized by IPSO to guarantee the generalization and learning abilities of the SVM model. To identify and construe the major influencing factors regarding carbon emissions of China's power industry - which will be considered as the appropriate inputs of the proposed model - we conducted grey relativity analysis (GRA).

\section{Material and Methods}

\section{Calculating Carbon Emissions}

Since China does not promulgate yearly carbon emissions for the power industry, this paper works out the raw data of power industry consumption carbon emissions from 1995 to 2014 through the conversion of energy combustion acquired from the China Energy Statistical Yearbook. It is noteworthy that almost no carbon is emitted in the use of solar, wind, or any renewable source of energy, so we just consider fossil energy in the calculation process of carbon emissions for China's power industry. Besides that, it is assumed that the oxidation rate of each fossil energy is set at $100 \%$.

On the basis of statistical definitions by the standards of the National Statistical Bureau, in this paper fossil energy is divided into three categories (coal and its products, oil and its products, and gas and its products) and combustion values of different kinds of energy are obtained for the power industry from the China Energy Statistical Yearbook. To ensure the comparability of measurement results, carbon emission coefficients of various types of energy adopt the recommended value of IPCC [26]. The specific calculation formula of carbon emissions is as follows:

$$
\mathrm{C}=\sum_{\mathrm{i}=1}^{3} \mathrm{C}_{\mathrm{i}}=\sum_{\mathrm{i}=1}^{3} \rho_{\mathrm{i}} * \gamma_{\mathrm{i}} * \mathrm{k}_{\mathrm{i}}
$$

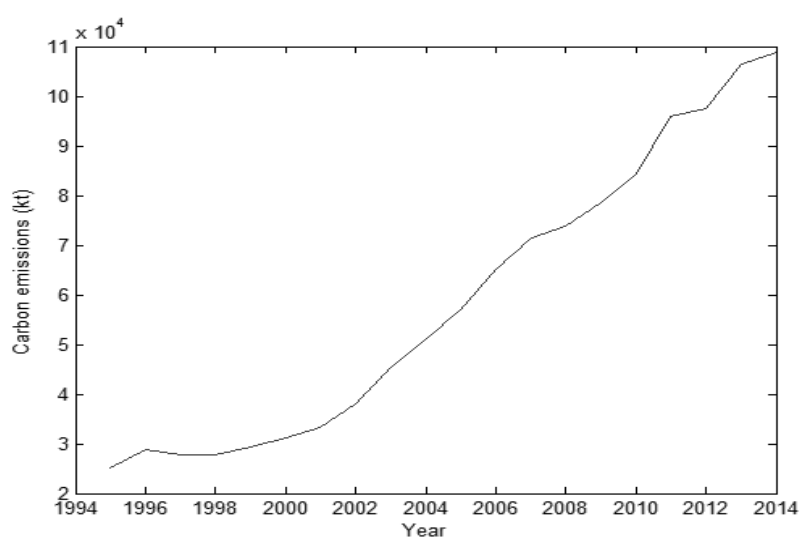

Fig. 1. Power industry carbon emissions of China, 1995-2014. ...where $\mathrm{C}$ represents carbon emissions emitted from the power industry, i refers to fossil fuel types, $\rho$ is energy consumption, $\gamma$ is the conversion coefficients of standard coal, and $\mathrm{k}$ is the carbon emissions coefficient.

On this basis, values of China's power industry carbon emissions from 1995 to 2014 are shown in Fig. 1. During this period, it illustrates that power industry carbon emissions increased from $25,059.65 \mathrm{kt}$ to $108,805.75 \mathrm{kt}$, with an average annual growth of $16.71 \%$.

\section{Grey Relativity Analysis (GRA)}

Due to the influences of socioeconomic development and the changes in policy environment, the numerous factors that could act on carbon emissions for the power industry tend to be nonlinear and nonstationary. And it is conceivable that the whole influencing factors can't be taken into account in forecasting carbon emissions for the power industry. Aiming at the characteristics of power industry carbon emissions, this paper identifies GDP, urbanization rate, total electricity consumption, the net coal consumption rate, and thermal power installed capacity as the major influencing factors based on the existing research. The related data is acquired from the China Statistical Yearbook and China Industrial Statistical Yearbook. Excluding price effect, the GDP is converted to 1978 prices by a GDP implicit deflator. Then the correlation degree of each factor and carbon emission is measured by the method of grey relativity analysis.

Grey relativity analysis is a theoretical method of grey system theory to judge the development trend of a selected system according to qualitative analyses and comparison. It can be used to obtain the grey correlation degree between reference sequence and comparison sequence through the comparison of geometric similarity of time series data in the system [27]. The method is not only suitable for time series data, but also for different individual and mass sample data - especially suitable for doing analysis of correlation and analysis of factor to few variables of un-linear correlation. When reference sequence and comparison sequence develop and change simultaneously, it will show a high grey correlation degree.

In the process of implementation, power industry carbon emissions are specified as a reference sequence, and influencing factors are first assigned comparison sequences. To exclude the influence of dimension and simplify the calculation, reference sequence and comparison sequences are converted into proper dimensions. Then we worked out the correlation degrees by GRA and the results showed that the grey relational degrees are all above the certain threshold of 0.6. Therefore, it can give no cause for much criticism of the interaction between power industry carbon emissions and influencing factors.

\section{Support Vector Regression (SVR)}

Support vector machine (SVM) is introduced by Cortes and Vapnik in 1995 [28] to deal with the problem of classification, which is based on the Vapnik-Chervonenkis 
dimension theory and structural risk minimization (SRM) of statistical learning theory [29]. This method has been extended to the domain of regression and prediction problems [30]. Among the current regression methods, SVM has several good properties, such as robustness and practicability for new samples due to the principle of SRM, the absence of local minima via convex optimization, and the simplicity in calculation only with simple optimization techniques. All these features increase the fitting degree and prediction accuracy of SVR. The architectural framework of SVR is shown in Fig. 2. A short introduction of how SVR effectively works is presented as follows.

A regression data set is expressed by $D=\left\{X_{i}, Y_{i}\right\}_{i=1}^{N}$, where $X_{i} \in R^{m}$ denotes the ith independent variable, $Y_{i} \in R^{m}$ the ith dependent variable, and $\mathrm{m}$ is the number of training patterns. SVR, which adopts the same principles as SVM for classification except a new type of loss function known as $\varepsilon$-insensitive loss function [31], is to construct the optimal separating hyper-plane with the error within $\varepsilon$. The optimization problem can be formulated as:

$$
\operatorname{Min} \frac{1}{2}\|w\|^{2}+c \sum_{i=1}^{N}\left(\xi_{i}+\xi_{i}^{*}\right)
$$

Subject to $\left\{\begin{array}{c}\mathrm{Y}_{\mathrm{i}}-\mathrm{w} \cdot \phi\left(\mathrm{X}_{\mathrm{i}}\right)-\mathrm{b} \leq \varepsilon+\xi_{\mathrm{i}} \\ -\mathrm{Y}_{\mathrm{i}}+\mathrm{w} \cdot \phi\left(\mathrm{X}_{\mathrm{i}}\right)+\mathrm{b} \leq \varepsilon+\xi_{\mathrm{i}}^{*} \mathrm{i}=1,2 \ldots \mathrm{N} \\ \xi_{\mathrm{i}} \geq 0, \xi_{\mathrm{i}}^{*} \geq 0\end{array}\right.$

...where $\mathrm{w}$ is the weight vector, $\xi_{\mathrm{i}}$ and $\xi_{\mathrm{i}}^{*}$ are slack variables to account for errors, $\phi\left(\mathrm{X}_{\mathrm{i}}\right)$ is a kernel function that can map the input space into a higher dimensional space, $c \in \mathrm{R}^{+}$is used as the error penalty factor that is adopted to check the trade-off between the regularization empirical and term risk, and $\mathrm{b}$ is a real constant.

In the process of solving this nonlinear programming problem, there are two important parameters that need to be determined. One is penalty parameter $\mathrm{c}$ mentioned above and the other is gamma $(\mathrm{g})$ in kernel function. The initial parameters are often randomly given or dependent on experience; therefore, the forecasting precision of SVR is limited. In addition, although the method of cross validation $(\mathrm{CS})$ to define $\mathrm{c}$ and $\mathrm{g}$ can overcome over-fitting and improve prediction performance, the convergence

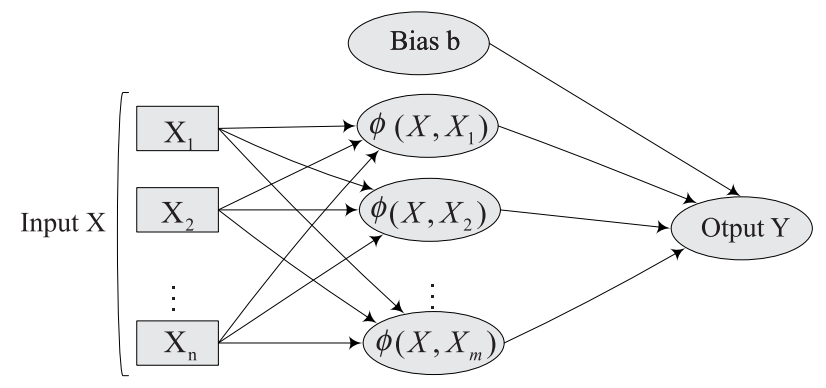

Fig. 2. Architectural framework of SVR. speed is very slow. Hence, a new PSO is proposed to accelerate convergence and improve forecast precision in this paper.

\section{Improved Particle Swarm Optimization}

(IPSO)

As a new branch of evolution algorithms, PSO was first developed by Eberhart and Kennedy [32] and is an effective intelligence algorithm that simulates the swarm behavior of birds. This evolutionary algorithm, which has been demonstrated as a powerful tool for solving optimization problems, is to find the solutions of a population represented by particles. For particle optimization, each particle represents a potential solution result, and each particle corresponds to a fitness value through an objective function determining the speed of particles determined in the direction and distance of a particle. These particles can coexist and they evolve simultaneously with their neighboring particles [33]. For the renewal of speed and position of each particle, certain formulas are shown as follows:

$$
\begin{gathered}
\mathrm{V}_{\mathrm{id}}^{\mathrm{k}+1}=\omega \mathrm{V}_{\mathrm{id}}^{\mathrm{k}}+\mathrm{c}_{1} \mathrm{r}_{1}\left(\text { pbest }_{\mathrm{id}}^{\mathrm{k}}-\mathrm{X}_{\mathrm{id}}^{\mathrm{k}}\right)+ \\
+\mathrm{c}_{2} \mathrm{r}_{2}\left(\text { gbest }_{\mathrm{gd}}^{\mathrm{k}}-\mathrm{X}_{\mathrm{id}}^{\mathrm{k}}\right) \\
\mathrm{X}_{\mathrm{id}}^{\mathrm{k}+1}=\mathrm{X}_{\mathrm{id}}^{\mathrm{k}}+\mathrm{V}_{\mathrm{id}}^{\mathrm{k}+1}
\end{gathered}
$$

...where $\mathrm{d}=1,2, \ldots, \mathrm{D}$ represents $\mathrm{dth}$ dimensional space, $\mathrm{i}=1,2, \ldots \mathrm{n}$ refers to ith particle, $\mathrm{k}$ indicates an iteration count, $\omega$ denotes the inertial weight, $c_{1}$ is the cognitive scaling parameter and $c_{2}$ is the social scaling parameter, $r_{1}$ and $r_{2}$ are random numbers uniformly distributed between 0 and $1, \mathrm{X}_{\mathrm{i}}=\left[\mathrm{x}_{\mathrm{i} 1}, \mathrm{x}_{\mathrm{i} 2}, \ldots, \mathrm{x}_{\mathrm{iD}}\right]^{\mathrm{T}}$ and $V_{i}=\left[V_{i 1}, V_{i 2}, \ldots, V_{i D}\right]^{T}$ respectively refer to the position and velocity of the ith particle, and pbest and gbest are respectively the individual extremum and the global extremum.

Although PSO has high convergence speed and high universality, it has the disadvantages of easy premature convergence, low search precision, and low efficiency of iteration [34-35]. In order to overcome these shortcomings, this paper will utilize the variation of ideas of genetic algorithm (GA) [36], and the mutation operation will be introduced in the PSO, that is reinitializing some variables with a certain probability. The mutation operation widens the constantly shrinking population search space in iteration so that particles can jump out of the previously searched optimal value position, and the search can be carried out in a larger space while preserving the diversity of the population as well as improving the algorithm to find the possibility of a better value position. Therefore, a simple mutation operator is introduced on the basis of ordinary PSO algorithm, and the particles will be reinitialized with a certain probability after each particle update. 


\section{IPSO-SVM Model}

In this section, power industry carbon emissions forecasting models incorporating IPSO and SVM are constructed as shown in Fig. 3. This paper chooses the sigmoid kernel function to map the original feature space into a high-dimensional space. And the epsilon in loss function of epsilon-SVR is set to 0.01 . The related data from 1995 to 2009 is selected as training samples, and the remaining data from 2010 to 2014 is regarded as test samples.

According to the IPSO-SVM model, the combinatory optimization of parameters can be acquired as follows:

- Step 1: Initialize the parameters of IPSO

Set the initial population size to 20 , and the maximum number of iteration is 100 times, and mutation probability is set to 0.6 . Moreover, the range of search space is $[-5,5]$ and velocity range is $[-1,1]$.

- Step 2: Calculate the fitness values

After adopting training error as the fitness function, calculate the fitness values of each particle. Then through comparing the fitness values, update the individual and global extremes, respectively.

- Step 3: Update parameters

According to formulae (4) and (5), update the speed and position of each particle.

- Step 4: Introduce mutation operation

Through the mutation operation, expand population search space. And then reselect the individual extremum and the global extremum.

- Step 5: Output the optimal solution

Sort all particle fitness values and find the current optimal solution. Repeat steps 2-4 up to the maximum number of iterations. Output the global optimal solution according to the optimal parameters and establish the power industry carbon emissions forecasting model.

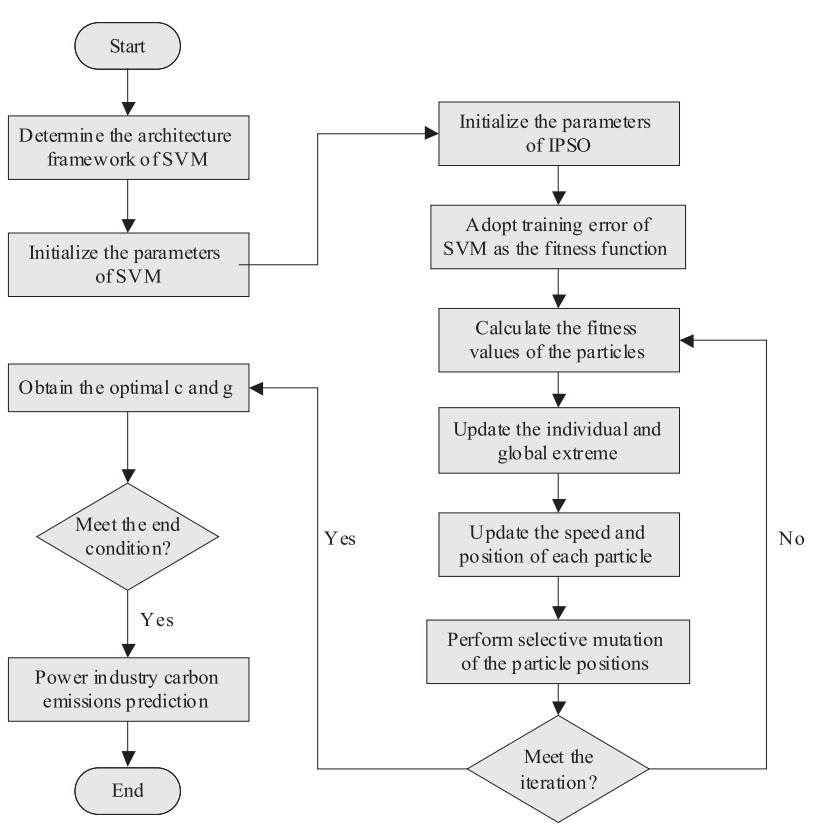

Fig. 3. Flowchart of the proposed model.

\section{Results and Discussion}

\section{Description of Scenarios}

According to the results of GRA, this paper designs scenarios based on different adjustment rates of economic growth, urbanization rate, total electricity consumption, net coal consumption rate, and thermal power installed capacity. The details of scenario settings are described as follows.

\section{Economic Growth}

At present, China's economy steps into the "new normal" phase after the economy's dramatic expansion over the previous two decades, as it is growing in a manageable and relatively balanced manner. In the dual pressures of economic downturn and steady growth, growth of China is facing a new challenge. Under this circumstance, the Chinese government takes a series of efficient measures to stimulate economic growth, such as implementation of the "Belt and Road" strategy, regional integration of Beijing-Tianjin-Hebei, reaction of the development of the Russian East Area, and the rejuvenation of northeast. China formulated "The $13^{\text {th }}$ Five-Year Plan" for social and economic development of the future five years on 3 November 2016. It has been proposed that the target average annual economic growth should not below $6.5 \%$ in the next five years. Taking into account both China's own actual development and the development plan mentioned, this paper respectively sets up three states - low-speed, medium-speed, and highspeed - for GDP growth, which correspond to growth rates of $6.5 \%, 6.8 \%$, and $7 \%$ according to the growth rate defined and estimating the values of real GDP in different schemes from 2016 to 2020 . The above results are shown in Table 1.

\section{Urbanization Rate}

Along with economic development, the stage of Chinese urbanization goes to accelerate development. But compared to developed countries, the level of urbanization is still relatively backward. Chinese premier Li Keqiang points out that China's urbanization rate is just over 50\%, and if calculated by household registered population, it is just about $35 \%$, which is far lower than developed

Table 1. Actual GDP, 2016-20 (unit: hundred million yuan).

\begin{tabular}{|c|c|c|c|}
\hline Year & Low-speed & Medium-speed & High-speed \\
\hline 2016 & $117,696.8298$ & $118,028.3702$ & $118,249.3971$ \\
\hline 2017 & $125,347.1237$ & $126,054.2993$ & $126,526.8549$ \\
\hline 2018 & $133,494.6868$ & $134,625.9917$ & $135,383.7347$ \\
\hline 2019 & $142,171.8414$ & $143,780.5591$ & $144,860.5961$ \\
\hline 2020 & $151,413.0111$ & $153,557.6371$ & $155,000.8379$ \\
\hline
\end{tabular}


Table 2. Urbanization rate, 2016-20

\begin{tabular}{|c|c|c|}
\hline Year & Low-speed & High-speed \\
\hline 2016 & 0.5688 & 0.5710 \\
\hline 2017 & 0.5766 & 0.5810 \\
\hline 2018 & 0.5844 & 0.5910 \\
\hline 2019 & 0.5922 & 0.6010 \\
\hline 2020 & 0.6000 & 0.6110 \\
\hline
\end{tabular}

countries with the near average level of $80 \%$. With the deepening reform of the household registration system and the increasing recognition of a city's function, the urbanization level of China will keep steadily increasing. The $13^{\text {th }}$ Five-Year Plan anticipates that China's urbanization rate will reach $60 \%$ or even more by 2020 . In view of this, the growth rate of urbanization is set to the low and high categories from 2016 to 2020. The above results are shown in Table 2.

\section{Total Electricity Consumption}

As the rain glass of the economy, total electricity consumption reflects the economic development level in a country. The amount of total electricity consumption increased to 569 million KW in 2015 from 101 million KW, with $20.79 \%$ annual increasing degree, on average. As the economy develops and living standards improve, the demand for electricity will grow continuously and steadily. In December 2016 the National Development and Reform Commission (NDRC) and National Energy Board (NEB) of China jointly issued the Electric Power Development Planning in the $13^{\text {th }}$ Five-Year Plan, which clearly points out that total electricity consumption is expected to reach 680-720 million KW, with an average growth of 3.6-4.8\%. For this reason, this paper establishes two kinds of states low-speed and high-speed - which correspond to growth rates of $3.6 \%$ and $4.8 \%$, then computes low and high schemes of the total electricity consumption from 2016 to 2020. And the results are displayed in Table 3.

\section{Net Coal Consumption Rate}

The net coal consumption rate is not only the critical economical examination indicator but also the

Table 3. Total electricity consumption, 2016-20 (unit: million KW).

\begin{tabular}{|l|l|l|}
\hline Year & Low-speed & High-speed \\
\hline 2016 & 589.825880 & 596.657840 \\
\hline 2017 & 611.059612 & 625.297416 \\
\hline 2018 & 633.057758 & 655.311692 \\
\hline 2019 & 655.847837 & 686.766654 \\
\hline 2020 & 679.458359 & 719.731453 \\
\hline
\end{tabular}

Table 4. Net coal consumption rate, 2016-20 (unit: $\mathrm{g} / \mathrm{kW} \cdot \mathrm{h}$ ).

\begin{tabular}{|c|c|c|}
\hline Year & Low-speed & High-speed \\
\hline 2016 & 314 & 314 \\
\hline 2017 & 313 & 312 \\
\hline 2018 & 312 & 311 \\
\hline 2019 & 311 & 309 \\
\hline 2020 & 310 & 308 \\
\hline
\end{tabular}

extraordinary important technique index for power plants. With the implementation of energy conservation, small units out of the grid and the adjustment of internal industrial structure of thermal power generation, great-capacity and high-parameter thermal power generating units are more and more useful, which promotes the reduction of net coal consumption. The Chinese government attaches great importance to the role of the net coal consumption rate reduction in power industry, and has set specific goals that promote reducing the net coal consumption rate to below $310 \mathrm{~g} / \mathrm{kW} \cdot \mathrm{h}$ by 2020 for active coal-fired units after the transformation. In accordance with the goals, the annual net coal consumption rates are shown below. And the results are displayed in Table 4.

\section{Thermal Power Installed Capacity}

For the last few years the thermal power installed capacity gradually decreased because of the development of new energy power generation such as wind, solar, and nuclear power. But the dominant role of thermal power will not change in the short term, which is restrained by a series of influencing factors - such as resource endowment, high cost, and technical level - causing thermal power installation capacity proportion to dip to $67.3 \%$ in 2014 . The $13^{\text {th }}$ Five-Year Plan for power industry explicitly points out that the total installed capacity will reach 2 billion $\mathrm{kW} \cdot \mathrm{h}$ and the thermal power installed capacity proportion will drop to $61 \%$ with an annual decreasing rate of $4 \%$ in 2020. Aiming at this goal, this paper sets up three kinds of situations and carries on the annual thermal power installed capacity separately. And the results are displayed in Table 5.

As shown in Table 6, according to different economic growth rates, the three main scenarios for China's power

Table 5. Thermal power installed capacity (unit: million KW).

\begin{tabular}{|c|c|c|}
\hline Year & Low-speed & High-speed \\
\hline 2016 & $10,484.32$ & $10,524.32$ \\
\hline 2017 & $10,913.24$ & $10,993.24$ \\
\hline 2018 & $11,342.16$ & $11,462.16$ \\
\hline 2019 & $11,771.08$ & $11,931.08$ \\
\hline 2020 & $12,200.00$ & $12,400.00$ \\
\hline
\end{tabular}




\begin{tabular}{|c|c|c|c|c|c|c|c|c|c|c|c|c|c|c|c|c|c|c|c|}
\hline & & $U_{H}$ & $\begin{array}{l}3 \\
0 \\
0 \\
-1\end{array}$ & $\stackrel{50}{.00}$ & 孞 & 每 & 古 & 点 & 古 & 点 & 蒿 & 点品 & 艿 & 点 & 艿 & 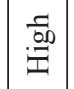 & 苟 & 点 & \\
\hline & & $\frac{n}{z}$ & 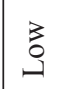 & | & 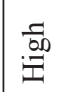 & $\begin{array}{l}\overline{50} \\
\overrightarrow{70}\end{array}$ & 艿 & 3. & $\begin{array}{l}\overline{5} \\
\overrightarrow{30} \\
\overrightarrow{3}\end{array}$ & 施 & $\begin{array}{l}3 \\
0 \\
0 \\
3\end{array}$ & 弪 & 超 & 官 & | & $\mid \begin{array}{l}3 \\
0 \\
0 \\
-1\end{array}$ & 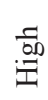 & 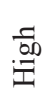 & \\
\hline & 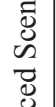 & $\underset{\mid I I}{u}$ & $\begin{array}{l}3 \\
0 \\
0 \\
-1\end{array}$ & $\begin{array}{l}3 \\
0 \\
0 \\
-1\end{array}$ & 艿 & 咅 & 昰 & 昰 & 昰 & 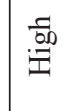 & 弪 & 蒿 & 艿 & 艿 & 点 & 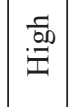 & 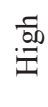 & 寄 & \\
\hline & 祍 & $\underline{s}$ & 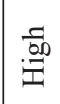 & 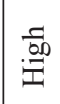 & 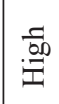 & 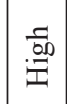 & 趈 & 点 & 趈 & 总 & 雚 & 茎 & 范 & 茎 & | & $\begin{array}{l}3 \\
0 \\
0 \\
0\end{array}$ & 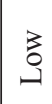 & 蒿 & \\
\hline & & U્ય & 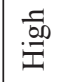 & 㿣 & 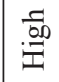 & $\mid \begin{array}{l}.50 \\
.00 \\
.07\end{array}$ & 点 & 焉 & 哥 & 焉 & 点 & 㺃 & 㺃 & 㺃 & 皇 & 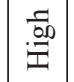 & 皇 & 点 & \\
\hline & & $n$ & $\begin{array}{l}\vec{n} \\
\text { II }\end{array}$ & బ్ & $\hat{n}$ & 志 & 点 & 足 & 站 & $\begin{array}{l}\infty \\
0 \\
0\end{array}$ & के & $\begin{array}{l}0 \\
\text { 公 } \\
\end{array}$ & $\overline{\bar{\sim}}$ & $\frac{1}{N}$ & 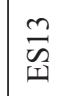 & $\left|\begin{array}{l} \pm \\
\vec{n} \\
\pm\end{array}\right|$ & $\frac{n}{2}$ & $\begin{array}{l}0 \\
\stackrel{0}{n} \\
\text { II }\end{array}$ & \\
\hline & & $\stackrel{U}{H}$ & $\begin{array}{l}3 \\
0 \\
0 \\
9\end{array}$ & 预 & 䓵 & 熍 & 3 & 章 & 莗 & 章 & 苟 & 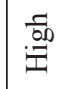 & 弪 & 氞 & 艿 & $\mid \begin{array}{l}\overrightarrow{50} \\
: \vec{\Xi}\end{array}$ & ב⿱ & 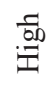 & \\
\hline & & 点 & 茎 & 蒿 & 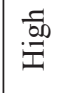 & 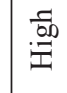 & 3 & 孞 & 童 & 童 & 艿 & 艿 & 童 & 童 & 艿 & $\mid \begin{array}{l}3 \\
0 \\
0 \\
-1\end{array}$ & 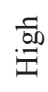 & 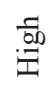 & \\
\hline 离 & $\begin{array}{l}\bar{\Xi} \\
\tilde{D} \\
\mathscr{n} \\
\Xi\end{array}$ & ن & 范 & 䓂 & 艿 & 吕 & 家 & 章 & 㞼 & 童 & 艿 & 艿 & 蒿 & 艿 & 童 & 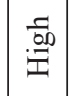 & 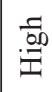 & 章 & \\
\hline 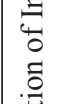 & 言 & 占 & 点 & 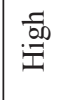 & 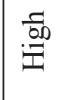 & 苟品 & 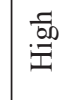 & 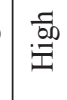 & 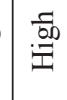 & 竘 & ) & 蒿 & 蒿 & 蒿 & 登 & $\begin{array}{l}3 \\
0 \\
0 \\
0\end{array}$ & 莗 & كُ & \\
\hline 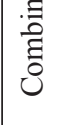 & & ن) & 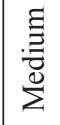 & 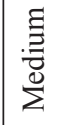 & 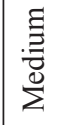 & 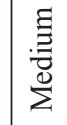 & 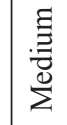 & 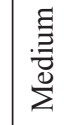 & 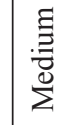 & 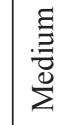 & 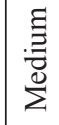 & 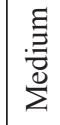 & 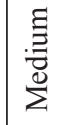 & 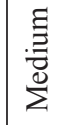 & 浔 & 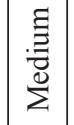 & 害 & $\begin{array}{l}\text { 䒜 } \\
\sum_{\Sigma}^{0}\end{array}$ & \\
\hline & & $\tilde{D}$ & $\overrightarrow{\tilde{O}}$ & है & $\tilde{\tilde{O}}$ & 苛 & $\tilde{n}$ & bे & $\tilde{n}$ & $\begin{array}{l}\infty \\
0 \\
0\end{array}$ & हे & $\frac{0}{\sqrt[n]{0}}$ & $\overline{\bar{n}}$ & $\frac{\pi}{\tilde{n}}$ & $\frac{m}{\sqrt{n}}$ & $\begin{array}{l} \pm \\
\bar{n}\end{array}$ & $\frac{n}{n}$ & $\frac{0}{\tilde{n}}$ & \\
\hline & & 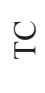 & 范 & 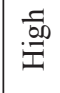 & 䓂 & 总 & 艿 & 章 & 艿 & 章 & 苟 & 每 & 艿 & 每 & 艿 & $\mid \begin{array}{l}.50 \\
.90\end{array}$ & కె & 犃 & \\
\hline & & 岂 & 范 & 䓂 & 每 & 点 & 永 & 蒿 & 占 & \begin{tabular}{l|l}
.$\overline{50}$ \\
.90
\end{tabular} & 苟 & 蒿 & 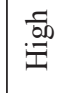 & 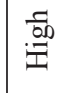 & 艿 & $\left|\begin{array}{l}3 \\
0 \\
0 \\
\end{array}\right|$ & $\stackrel{\sqrt{600}}{.1}$ & 离 & \\
\hline & 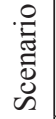 & ن & 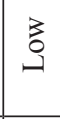 & 艿 & 夯 & 疍 & 点 & 㝒 & 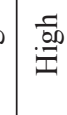 & \begin{tabular}{|l|l}
.50 \\
:
\end{tabular} & 蒿 & 蒿 & | & | & 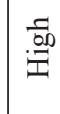 & 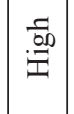 & 窇施 & 点点 & \\
\hline & 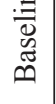 & s. & 害 & 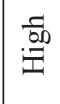 & 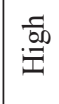 & 它施 & 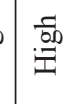 & 它施 & 熍 & 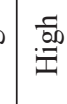 & 蒿 & 蒿 & 蒿 & 艿 & 艿 & $\begin{array}{l}3 \\
0 \\
0 \\
\end{array}$ & 30 & 3) & \\
\hline & & ن) & 永 & 永 & 水 & 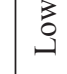 & 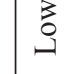 & 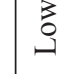 & $\stackrel{3}{0}$ & 苞 & كِ & (3) & 年 & | & 䚄 & $\begin{array}{l}3 \\
0 \\
0 \\
9\end{array}$ & (3) & ؛ & \\
\hline & & 战 & $\overrightarrow{\tilde{n}}$ & है & $\tilde{n}$ & 岕 & $\tilde{n}$ & ஜ & $\tilde{n}$ & 表 & के & $\frac{0}{\infty}$ & $\overline{\bar{n}}$ & $\frac{\sim}{\tilde{n}}$ & $\frac{m}{n}$ & $\begin{array}{l} \pm \\
\tilde{n}\end{array}$ & $\frac{n}{n}$ & $\vec{\bullet}$ & \\
\hline
\end{tabular}


industry - the baseline scenario (BS), the optimization scenario (OS), and the enhanced scenario (ES) - are designed. Then 48 series are provided in this study through a combination of the three main scenarios and the variation rate of each index set out above.

\section{Model Performance Evaluation}

To corroborate the excellent performance of the IPSOSVM model, GM $(1,1)$ and BP neural network model are also employed to predict carbon emissions. Then, two criteria - mean absolute percentage error (MAPE) and the coefficient of determination (R2) - are selected to quantitatively measure the performance of the involved models. With the interval of $[0,1]$, the closer the value of $\mathrm{R} 2$ is to 1 , the better the performance of the model. The formulas of the aforementioned criteria are presented as follows:

$$
\begin{array}{r}
\text { MAPE }=\frac{1}{n} \sum_{i=1}^{n}\left|\frac{y_{i}-\widehat{y}_{1}}{y_{i}}\right| \\
R^{2}=1-\frac{\sum_{i=1}^{n}\left(y_{i}-\widehat{y}_{l}\right)^{2}}{\sum_{i=1}^{n}\left(\hat{y}_{i}-\bar{y}\right)^{2}}
\end{array}
$$

...where $\mathrm{n}$ denotes the number of the carbon emissions to be forecast, $y_{i}$ represents the real value in the ith year, $\widehat{y}_{1}$ is the forecasted value, and $\bar{y}$ is the average value of the forecasted value.

Fig. 4 shows the forecast results with different models from 2010 to 2014, where IPSO-SVM has a higher fitting degree. Since $\operatorname{GM}(1,1)$ relies heavily on its original data, without consideration of the influencing factors, its forecast results take on an approximately linear increasing trend. The reason why the prediction results of the BP model misfit the wave characteristics of carbon emissions tends to be attributed to the shortcoming that the result of BP is easy to trap in local optimum. From Table 7, it can be concluded that IPSO-SVM shows high reliability and

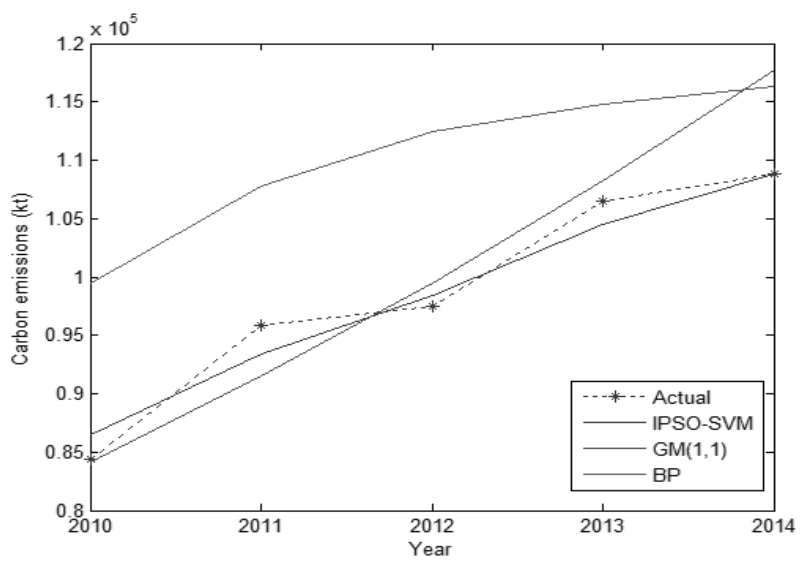

Fig. 4. Comparison of forecast results with different models.
Table 7. Error analysis of carbon emissions.

\begin{tabular}{|c|c|c|c|}
\hline Index & IPSO-SVM & GM $(1,1)$ & BP \\
\hline MAPE & 0.156 & 0.033 & 0.372 \\
\hline R2 & 0.9651 & 0.921 & 0.941 \\
\hline
\end{tabular}

high accuracy based on the assessment results of MAPE and R2, since the model has the ability to approach any nonlinear function precisely. Based on the above reasons, this paper will employ the IPSO-SVM model to forecast carbon emissions for China's power industry up to 2020 .

\section{Forecast of Carbon Emissions in Baseline Scenario}

In the baseline scenario, economic growth is assumed to be at a low rate through the 2016, and there are 16 kinds of scenario sequences. The predicted values of each sequence for China's power industry carbon emissions are shown in Fig. 5.

From Fig. 5, it can be seen that the prediction results of carbon emissions from 2016 to 2020 show an upward trend for all scenario sequences. The results reveal that there is a very large range for the variation of the value estimate of carbon emissions. The minimum of carbon emissions occurs in scenarios BS2, in which the urbanization rates are at a high speed and total electricity consumption, net coal consumption rates, and thermal power installed capacity are at low speed, low-speed, and high-speed, respectively, and the forecasting value in 2020 is $128,928.27 \mathrm{kt}$. While the maximum carbon emissions exists in scenario BS6, where the urbanization rates are at low speed and total electricity consumption, net coal consumption rate, and thermal power install capacity are at high speed, low speed, and high speed, respectively, and the estimation value in 2020 is $133,907.68 \mathrm{kt}$. A comparison of the two series indicates that total electricity consumption plays an important role in carbon emissions increase. Furthermore, through the comparison of BS2 and BS3, BS6 and BS7,

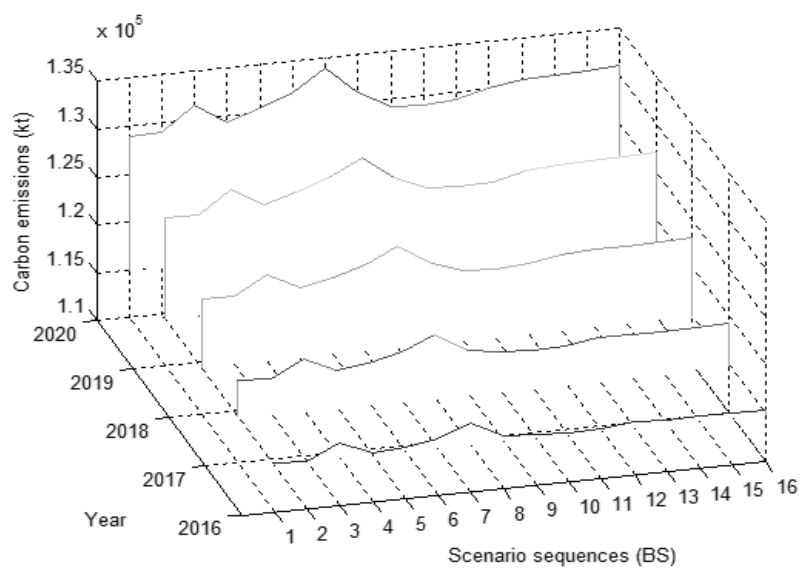

Fig. 5. Prediction values of China's power industry carbon emissions for the baseline scenarios, 2016-20. 
BS10 and BS11, BS14 and BS15, it can be found that the contribution of the net coal consumption rate on the reduction of carbon emissions is higher than the thermal power installed capacity.

\section{Forecast of Carbon Emissions in Optimization Scenario}

The optimization scenario encompasses 16 kinds of series, and the economic development of these series is set to the medium-speed. The predicted values of China's power industry carbon emissions are displayed in Fig. 6.

The prediction results illustrate that there is a rising trend in power industry carbon emissions within the year frame of 2016-20. Compared to forecast results of the baseline scenario, the range of fluctuation is much larger for the optimization scenario. The minimum of carbon emissions is $128,691.59 \mathrm{kt}$ with a low speed adjustment rate of the urbanization rate, total electricity consumption, net coal consumption rate, and thermal power installed capacity, which appear in scenarios OS9. The maximum carbon emissions occur in scenarios OS3, in which the urbanization rates are at high speed and total electricity consumption, net coal consumption rates, and thermal power installed capacity are at low speed, high speed, and low speed, and the prediction value in 2020 is $136,345.15 \mathrm{kt}$. Contrast the two different scenarios, and it is noteworthy that high-speed urbanization will drive a tremendous amount increase of carbon emissions, which exceeds the inhibitory effect of the net coal consumption rate reduction. There is a paramount reason for this phenomenon, namely that the adjustment rate of the net coal consumption rate is relatively low. The same conclusion can also be reached by comparing scenarios OS4 and OS10. In addition, by comparing OS2 and OS3, OS6 and OS7, OS10 and OS11, and OS14 and OS15, the contribution of the net coal consumption rate adjustment on carbon emissions reduction is higher than that of the thermal power installed capacity adjustment.

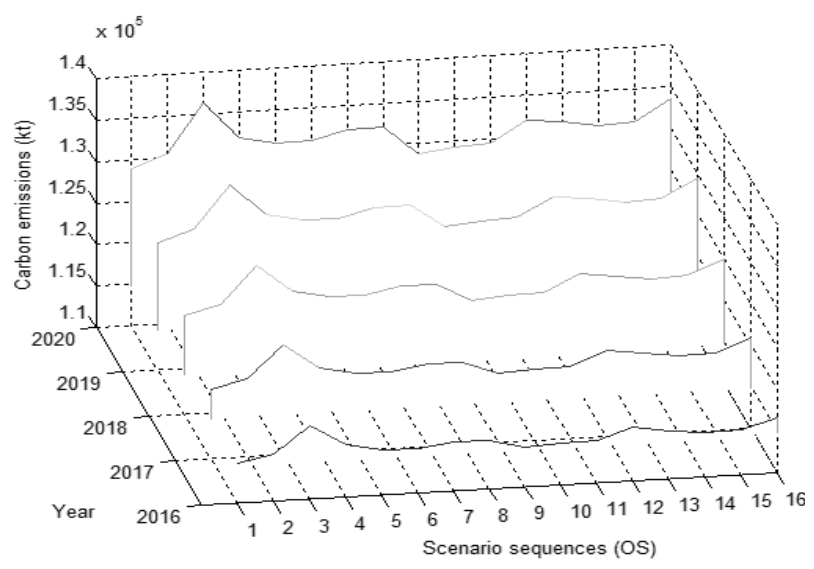

Fig. 6. The prediction values of China's power industry carbon emissions for optimization scenarios, 2016-20.

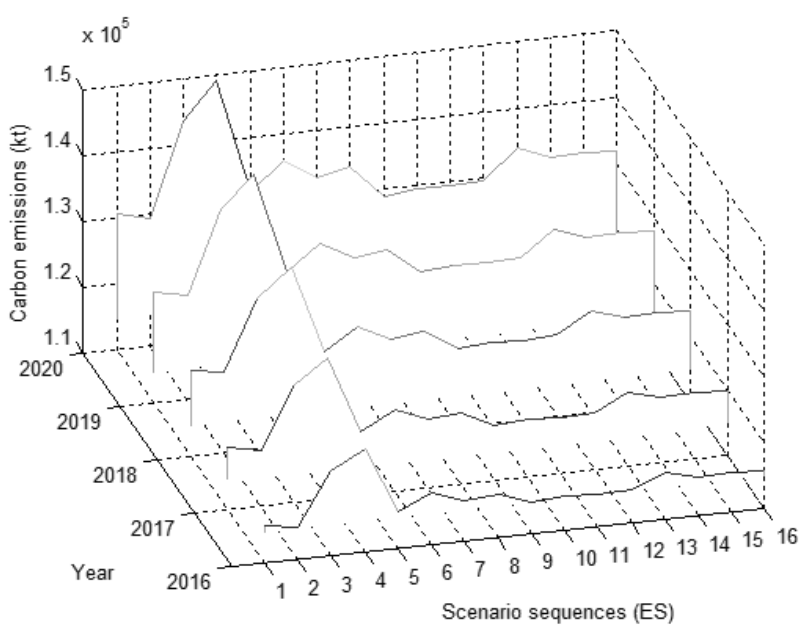

Fig. 7. Prediction values of China's power industry carbon emissions for enhanced scenarios, 2016-20.

\section{Forecast of Carbon Emissions in Enhanced Scenario}

In the enhanced scenario, the pace of economic development is supposed to at a high-speed, and there are altogether 16 kinds of situations in this case. The predicted values of China's power industry carbon emissions are present in Fig. 7.

From Fig. 7, it can be concluded that no matter what the situation, carbon emissions continue to expand during the study period. There are great differences in the extent of variation of the predicted carbon emissions in different situations. The minimum of carbon emissions exists in scenarios ES9, in which urbanization rates, total electricity consumption, net coal consumption rates, and thermal power installed capacity are all at a low speed, and the forecasting value in 2020 is $128,913.96$ kt. Meanwhile, maximum carbon emissions emerges in scenario ES4, where the urbanization rates are at high speed and total electricity consumption, net coal consumption, and thermal power installed capacity are at low speed, high speed, and high speed, respectively, and the prediction value in 2020 is 149,137.32 kt. Combined with differences between the two situations, it elucidates that the accelerating development of urbanization and the quick increase of thermal power installed capacity exert positive influences on the increase of carbon emissions.

\section{Comparison of Scenarios}

By analyzing and comparing and combining prediction results of the three scenarios, it can be found that carbon emissions of China's power industry will reach 128,691.59-149,137.32 kt in 2020. However, carbon emissions of China's power industry and economic growth demonstrate no coherence, and higher economic growth does not mean higher carbon emissions. The comparisons of BS1 and OS1, BS6 and OS6, BS7 and OS7, BS8 and OS8, BS9 and OS9 and ES9, OS12 and ES12, and OS16 
and ES16 can corroborate the phenomenon of decoupling between carbon emissions of China's power industry and economic growth. The main reasons may be that the mode of China's economic growth has been transforming from extensive and intensive, and new energy industry has achieved rapid development in recent years due to its environmental advantages and falling costs.

\section{Conclusions}

On the basis of the IPSO-SVM model, this study constructs a scenario analysis model of China's power industry carbon emissions. Due to the volatility of carbon emissions, SVM is exploited to simulate and forecast carbon emissions. The IPSO model is employed to choose the fine-tuned parameters of SVM. Considering the carbon emissions affected and restricted by multitudinous factors, GRA is used to identify and analyze the major influencing factors as the inputs of the proposed model. By comparing different models, the IPSO-SVM model shows the best forecasting performance.

Based on different adjustment rates of economic growth, the urbanization rate, total electricity consumption, the net coal consumption rate, and thermal power installed capacity, this study designs three kinds of carbon emission scenarios (including 48 development scenarios) to forecast carbon emissions of China's power industry up to 2020. Different development scenarios have different prediction results that indicate that carbon emissions of China's power industry will be $128,691.59-149,137.32 \mathrm{kt}$ in 2020. The influencing level of each factor differs a lot in different development scenarios. Furthermore, there exists a certain decoupling effect between carbon emissions of China's power industry and economic growth.

\section{Acknowledgements}

This study was supported by the Humanities and Social Sciences Planning Foundation of the Ministry of Education of China (grant No. 16YJA790052).

\section{References}

1. WHITE C.M., STRAZISAR B.R., GRANITE E.J., HOFFMAN J.S., PENNLINE H.W. Separation and Capture of $\mathrm{CO}_{2}$ from Large Stationary Sources and Sequestration in Geological Formations-Coalbeds and Deep Saline Aquifers. Journal of the Air \& Waste Management Association, 53, 645, 2003.

2. IEA, 2007a. World Energy Outlook 2007: China and India Insights. International Energy Agency: Paris, 2007.

3. BIROL F. World Energy Outlook 2013. International Energy Agency: Paris, 2013.

4. YANSHA Y., GUNFEN H., WEIBIN L., JIANG W. Research on Several Problems of Power Development in the 12th Five-Year Plan, China Electric Power Press: Beijing, China, 2010.
5. SCHMALESEE R., STOKER T.M., JUDSON R.A. Word carbon dioxide emission: 1950-2050. Review of Economics \& Statistics, 80, 15, 1998.

6. AROURI M.E.H., YOUSSEF A.B., HENNI H.M., RAULT C. Energy consumption, economic growth and $\mathrm{CO}_{2}$ emission in Middle East and North African countries. Energy Policy, 45, 342, 2012.

7. SABOORI B., SULAIMAN J., MOHD S. Economic growth and $\mathrm{CO} 2$ emissions in Malaysia: A cointegration analysis of the environment Kuznets curve. Energy Policy, 51 (4), 184, 2012.

8. GALEOTTI M., LANZA A., PAULI F. Reassessing the environmental Kuznets curve for $\mathrm{CO}_{2}$ emissions: a robustness exercise. Ecological Economics, 57 (1), 152, 2006.

9. WANG S.S., ZHOU D.Q., ZHOU P., WANG Q.W. $\mathrm{CO}_{2}$ emissions, energy consumption and economic growth in China: a panel data analysis. Energy Policy, 39 (9), 4870, 2011.

10. WU H., GU S.Z., GUAN X.Y., LU S.S. The relationship between the carbon emissions of fossil energy consumption and the economic growth in China. Journal of Cleaner Production, 3, 381, 2013.

11. MI Z.F., PAN S.Y., YU H., WEI Y.M. Potential impacts of industrial structure onenergy consumption and $\mathrm{CO}_{2}$ emission: a case study of Beijing. Journal of Cleaner Production, 103, 455, 2015

12. DALY H.E., SCOTT K., STRACHAN N., BARRETT J. The indirect $\mathrm{CO}_{2}$ emission implications of energy system pathways: linking IO and times models for the UK. Environmental Science Technology, 49 (17), 10701, 2015.

13. SHAHBAZ M., SBIA R., HAMDI H., OZTURK I. Economic growth, electricity consumption, urbanization and environmental degradation relationship in United Arab Emirates. Ecological Indicators, 45 (5), 622, 2014.

14. FAN Y., LIU L.C., WU G., WEI Y.M. Analyzing impact factors of $\mathrm{CO}_{2}$ emissions using the STIRPAT model. Environmental Impact Assessment Review, 26 (4), 377, 2006.

15. SU B., ANG B.W. Multi-region comparisons of emission performance: the structural decomposition analysis approach. Ecological Indicators, 67, 78, 2016.

16. FARHANI S., CHAIBI A., RAULT C. $\mathrm{CO}_{2}$ emissions, output, energy consumption, and trade in Tunisia. Economic Modelling, 38, 426, 2014.

17. AL-MULALI U., SHEAU-TING L. Econometric analysis of trade, exports, imports, energy consumption and $\mathrm{CO} 2$ emission in six regions. Renewable \& Sustainable Energy Reviews, 33 (2), 484, 2014.

18. WANG Z., DANG Y.G. Research on carbon emission prediction in Jiangsu Province based on an improved GM $(1,1)$ model. IEEE International Conference on Gray System, 93, 2013.

19. ZHENGXIN W., DEJUN Y. Forecasting Chinese carbon emissions from fossil energy consumption using non-linear grey multivariable models. Journal of Cleaner Production, 142, 600, 2017.

20. DU Q., CHEN Q., YANG R. Forecast carbon emissions of provinces in China based on logistic model. Resources Environment in the Yangtze Basin, 122, 143, 2013.

21. SUN W., LIU M. Prediction and analysis of the three major industries and residential consumption $\mathrm{CO}_{2}$ emissions based on least squares support vector machine in China. Journal of Cleaner Production, 122, 144, 2016

22. LIU X., MAO G., REN J., LI R.Y.M., GUO J., Zhang, L. How might China achieve its 2020 emissions target? A scenario analysis of energy consumption and $\mathrm{CO}_{2}$ emissions 
using the system dynamics model. Journal of Cleaner Production, 103, 401, 2015.

23. GAMBHIR A., SCHULZ N., NAPP T., TONG D., MUNUERA L. A hybrid modeling approach to develop scenarios for China's carbon dioxide emissions to 2050. Energy Policy, 59 (59), 614, 2013.

24. ZHANG Y., WANG C., WANG K., CHEN J. CO2 emission scenario analysis for China's electricity sector based on LEAP software. Journal of Tsinghua University, 47(3), 365, 2007.

25. YUAN J., NA C., HU Z., LI P. Energy Conservation and Emissions Reduction in China's Power Sector: Alternative Scenarios Up to 2020. Energies, 9 (4), 266, 2016.

26. IPCC 2006, 2006 IPCC Guidelines for National Greenhouse Gas Inventories, Prepared by the National Greenhouse Gas Inventories Programme, Eggleston H.S., Buendia L., Miwa K., Ngara T. and Tanabe K. (eds). Published: IGES, Japan.

27. LIU S.F., CAI H., YANG Y.J., YING C. Research progress of grey relational analysis model. Systems Engineering \& Theory Practice, 33, 2041, 2013.

28. CORTES C., VAPNIK V. Support-vector networks. Machine Learning, 20 (3), 273, 1995.

29. CHANG C.C., LIN C.J. LIBSVM: A library for support vector machines. ACM Trans. Acm Transactions on Intelligent Systems \& Technology, 2 (3), 27, 2011.
30. SMOLAA., VAPNIK V. Support vector regression machines. Advances in Neural Information Processing Systems, 9, 155, 1977.

31. VAPNIK V.N., GOLOWICH S.E., SMOLA A. Support Vector Method for Function Approximation, Regression Estimation, and Signal Processing. Advances in Neural Information Processing Systems, 281, 1996.

32. POLI R., KENNEDY J., BLACKWELL T. Particle swarm optimization. Swarm Intelligence, 1 (1), 33, 2007.

33. JIN G., FAN Z.W., WANG C., GUO W.P., LAI X.M., CHEN M.Z. A minimum-of-maximum relative error support vector machine for simultaneous reverse prediction of concrete components. Computer \&Structures, 172 (C), 59, 2016.

34. LIANG J.J., QIN A.K., SUGANTHAN P.N., BASKAR S. Comprehensive learning particle swarm optimizer for global optimization of multimodal functions. IEEE Transactions on Evolutionary Computation, 10 (3), 281, 2006.

35. JORDEHI A.R. Enhanced leader PSO (ELPSO): a new PSO variant for solving global optimization problems. Applied Soft Computing, 26 (26), 401, 2015.

36. SUN W., XU Y. Using a back propagation neural network based on improved particle swarm optimization to study the influential factors of carbon dioxide emissions in Hebei Province, China. Journal of Cleaner Production, 112, 1282, 2016. 